\title{
Frequency and Clinical Significance of Appendectomy and Tonsillectomy in Patients with Inflammatory Bowel Disease
}

\author{
(D) Yasemin Gökden ${ }^{1}$, (D) Deniz Öğütmen Koç² \\ 1 University of Health Sciences Turkey, Prof. Dr. Cemil Taşçıoğlu City Hospital, Clinic of Gastroenterology, İstanbul, Turkey \\ 2 University of Health Sciences Turkey, Gaziosmanpaşa Training and Research Hospital, Clinic of Gastroenterology, Istanbul, Turkey
}

\section{Abstract}

Objective: Appendectomy and tonsillectomy remain controversial environmental factors in the etiology of inflammatory bowel disease (IBD). In this study, we aimed to investigate the frequency of tonsillectomy and appendectomy in patients with IBD. In addition, the effects of tonsillectomy and appendectomy on age of IBD diagnosis, site of intestinal involvement, and medical treatments were investigated.

Methods: A total of 131 IBD patients and 76 healthy controls (HCS) were included in this study. All of these patients included in this study were asked if they had undergone an appendectomy or tonsillectomy and their age at the time of the surgery. The age of diagnosis of IBD, medical treatment, disease location, and perianal involvement characteristics of the patients collected from the hospital records were evaluated.

Results: Of 90 patients with ulcerative colitis (UC), 2 patients underwent appendectomy after the age of 20 and after the diagnosis of UC. Compared with HCs, appendectomy and the age during operation were not associated with the incidence of UC. Moreover, 8 of 41 patients with Crohn's disease (CD) had undergone appendectomy. Of these, 6 patients had undergone surgery before the age of 20 and before the diagnosis of CD. Compared with HCS, appendectomy and the operative age were significantly associated with the incidence of CD. No significant relationship was observed between the groups in terms of tonsillectomy.

Conclusion: Appendectomy was associated with an increased risk of developing CD; however, no effect was observed on the risk of developing UC. Moreover, tonsillectomy was not associated with an increased risk of incidence of both CD and UC.

Keywords: Inflammatory bowel disease, appendectomy, tonsillectomy

\section{INTRODUCTION}

Inflammatory bowel disease (IBD) is a chronic inflammatory disease of the gastrointestinal system that occurs with periods of activity and remission. Ulcerative colitis (UC) and Crohn's disease (CD) are the 2 main forms of IBD and separate from each other by their endoscopic and pathological findings (1). The etiopathogenesis of IBD is multifactorial and has not yet been fully understood. However, it is believed that genetic and environmental factors trigger the disease (2). Environmental factors and those affecting the microbiota are held responsible for the occurrence of the disease in people with a genetic predisposition (3). Considering the close relationship of the intestinal content with the mucosal immune system, the microbiota appears to be the most important environmental risk factor for IBD.

The tonsils, appendix, and Peyer's patches are the most important components of the mucosa-associated lymphoid tissue. Therefore, appendectomy and tonsillectomy are among the main environmental factors that affect the structure of the intestinal bacteria (4). Appendectomy and tonsillectomy, namely MALTectomy, can cause changes in intestinal immunity $(5,6)$. MALTectomy and the resulting immune changes have been associated with IBD and many diseases with autoimmune components and end-organ inflammation $(7,8)$. The results of

Phone: +90 2122217777 E-mail: yasemingokden@hotmail.com ORCID ID: orcid.org/0000-0001-6767-3072

Cite this article as: Gökden Y, Ögütmen Koç D. Frequency and Clinical Significance of Appendectomy and Tonsillectomy in Patients with Inflammatory Bowel Disease. Eur Arch Med Res 2021;37(1):38-44

๑Copyright 2021 by the University of Health Sciences Turkey, Prof. Dr. Cemil Taş̧̧ığlu City Hospital

European Archives of Medical Research published by Galenos Publishing House. 
studies investigating the relationship between appendectomy, tonsillectomy, and IBD are contradictory $(6,9,10)$.

Smoking and appendectomy are among the most important environmental risk factors identified for IBD (11). Moreover, the risk of appendectomy was reported to be increased among children whose parents have smoking habit (12). This finding further complicates the relationship between smoking, appendectomy, and IBD.

In our study, we investigated the prevalence of tonsillectomy and appendectomy, which is thought to cause changes in the intestinal microbiome and affect intestinal mucosal immunity in UC and CD patients. In addition, we evaluated the effects of tonsillectomy and appendectomy and the age during operation on age of IBD diagnosis, disease location, and medical treatment. We also investigated the relationship of smoking with appendectomy and tonsillectomy in IBD patients.

\section{METHODS}

This study protocol conformed to the Declaration of Helsinki and was approved by the Ethics Committee of the University of Health Sciences, University of Health Sciences Turkey, Prof. Dr. Cemil Taşçıŏglu City Hospital (number: E-48670771-514.10, date: 26.01.2021). Informed consent was obtained from all participants of this study for analysis and publication of their data for scientific purposes.

In total, 131 IBD patients, including 90 patients with UC and 41 patients with $C D$, who were followed-up from the gastroenterology clinic and whose diagnosis of IBD was definite endoscopically, pathologically, and radiologically, were enrolled in the study. Patients $<18$ years of age, patients with incomplete information in their patient files and incomplete answers to questions, and patients with an uncertain diagnosis of IBD were excluded from the study. Healthy controls (HCS) who were matched in terms of age and gender were also included in the study. People who applied to the hospital for their routine check-up and had no known diseases, malignancy, or drug history were selected to be part of the HCs group.

The IBD patients and the HCs participants were asked about the history of appendectomy or tonsillectomy, their age at the time of surgery, their smoking habits, and the smoking status of their parents to understand their general nicotine exposure.

In this study, we collected data on the age of diagnosis of IBD, medical treatment, disease location, and perianal involvement characteristics of patients from the hospital records and evaluated them. Patients with UC were grouped as proctitis, distal colitis, left-sided colitis, and pancolitis according to the disease site. Patients with CD were grouped as ileal, colonic, and ileocolonic.

\section{Statistical Analysis}

The compatibility of numerical variables to normal distribution was tested using the Shapiro-Wilk test. The Mann-Whitney U test was used for comparing numerical variables that were not normally distributed in two groups, and the Kruskal-Wallis test was used for comparison of three groups. Relationships between categorical variables were tested using the chi-squared test. The risk of developing CD in those who underwent appendectomy was calculated using odds ratio (OR). IBM SPSS Statistics for Windows, version 22.0 (IBM Corp., Armonk, NY, USA) was the software used for the statistical analyses. The $p$ value $<0.05$ was considered significant.

\section{RESULTS}

The study included 90 patients (45 male, 50\%) with UC, 41 patients (27 male, 65.9\%) with CD, and $76 \mathrm{HCs}$ (37 male, 48.7\%). The median age of UC patients was 38 [interquartile range (IQR): $30-51$ ] years, CD patients was 40 (IQR: 35-45) years, and the HCS was 37 (IQR: 29-47) years. No significant difference was observed between the groups in terms of age, gender, body mass index, family history of IBD, and smoking status ( $p>0.05)$. In addition, no relationship was found between nicotine exposure in IBD patients (due to smoking habits of their parents or of their own), appendectomy, and tonsillectomy. However, we observed that the appendectomy rate was higher in $C D$ patients compared with that of $U C$ patients and the HCs $(p=0.001)$. Demographic and clinical characteristics of UC and CD patients and the HCs are shown in Table 1.

\section{Appendectomy}

In this study, 2 of 90 UC patients (2.2\%) underwent appendectomy after the age of 20 and after the diagnosis of UC. Compared with the HCs, no association was observed between appendectomy and the age during surgery in patients with UC ( $p=0.287, p=0.414$, respectively; Table 2$)$. The mean (standard deviation) time from the diagnosis of UC to appendectomy was 8.5 (2.1) years. The mean followup period of the two patients who underwent appendectomy was 14.5 (0.7) years. No significant difference was observed between patients with UC who had undergone appendectomy and those who did not undergo appendectomy, in terms of drug use (corticosteroids, azathioprine/6-mercaptopurine, or anti-tumor necrosis factor agents) and disease location ( $p>0.05$; Table 3, 4). 
Furthermore, we found that appendectomy was performed in 8 (19.5\%) of 41 patients with CD. Of these, 6 patients (75\%) had undergone surgery before the age of 20 and before the diagnosis of $\mathrm{CD}$. The mean time from appendectomy to the diagnosis of CD was 16 (13.3) years. The mean follow-up period of these patients after the diagnosis of CD was 5.8 (3.5) years. In terms of disease location and drug use, no significant difference was found between CD patients who had undergone appendectomy and those who did not undergo appendectomy $(p>0.05)$. Compared with the HCs, appendectomy and operative age were significantly associated with the incidence of $C D$ ( $p=0.019$, both). The probability of developing CD was 4.3 times higher in patients with appendectomy (OR: 4.30, 95\% Cl: 1.20-15.31).

\begin{tabular}{|c|c|c|c|c|}
\hline & $\begin{array}{l}\mathrm{UC} \\
(\mathrm{n}=90)\end{array}$ & \begin{tabular}{|l|}
$\mathrm{CD}$ \\
$(\mathrm{n}=41)$
\end{tabular} & \begin{tabular}{|l|} 
Control \\
$(\mathrm{n}=76)$
\end{tabular} & p \\
\hline \multicolumn{5}{|l|}{ Sex, n (\%) } \\
\hline Male & $45(50.0)$ & $27(65.9)$ & $37(48.7)$ & 0.165 \\
\hline Female & $45(50.0)$ & $14(34.1)$ & $39(51.3)$ & - \\
\hline Age, median (IQR) & $38.0(30.0-51.0)$ & $40.0(35.0-45.0)$ & $37.0(29.0-47.5)$ & 0.840 \\
\hline BMI, median (IQR) & $24.7(22.0-27.2)$ & $25.4(23.8-27.2)$ & $24.0(22.0-27.0)$ & 0.302 \\
\hline Smoker & $30(33.3)$ & $18(43.9)$ & $31(40.8)$ & 0.431 \\
\hline Family history & $7(21.9)$ & $0(0.0)$ & - & 0.132 \\
\hline Disease onset age median (IQR) & $32.0(25.0-43.0)$ & $32.0(28.0-39.0)$ & - & 0.800 \\
\hline \multicolumn{5}{|l|}{ Appendectomy, n (\%) } \\
\hline Yes & $2(2.2)$ & $8(19.5)$ & $4(5.3)$ & $0.001^{*}$ \\
\hline No & $88(97.8)$ & $33(80.5)$ & $71(94.7)$ & - \\
\hline \multicolumn{5}{|l|}{ Tonsillectomy, n (\%) } \\
\hline Yes & $7(7.8)$ & $2(4.9)$ & $5(6.7)$ & 0.828 \\
\hline No & $83(92.2)$ & $39(95.1)$ & $70(93.3)$ & - \\
\hline
\end{tabular}

\begin{tabular}{|c|c|c|c|c|c|c|}
\hline \multirow[b]{2}{*}{ Age (year) } & \multicolumn{2}{|c|}{ Appendectomy } & \multirow[b]{2}{*}{$\mathrm{p}$} & \multicolumn{2}{|c|}{ Tonsillectomy } & \multirow[b]{2}{*}{ p } \\
\hline & $<20$ & $>20$ & & $<20$ & $>20$ & \\
\hline UC, n (\%) & $0(0.0)$ & $2(100)$ & \multirow{2}{*}{0.414} & $6(85.7)$ & $1(14.3)$ & \multirow{2}{*}{0.398} \\
\hline Control, n (\%) & $0(0.0)$ & $4(100)$ & & $5(100)$ & $0(0.0)$ & \\
\hline CD, n (\%) & $6(75)$ & $2(25)$ & \multirow{2}{*}{$0.019 *$} & $0(0.0)$ & $2(100)$ & \multirow{2}{*}{$0.014^{*}$} \\
\hline Control, n (\%) & $0(0.0)$ & $4(100)$ & & $5(100)$ & $0(0.0)$ & \\
\hline
\end{tabular}

\begin{tabular}{|c|c|c|c|c|c|c|}
\hline & \multicolumn{2}{|c|}{ Appendectomy } & \multirow[b]{2}{*}{$p$} & \multicolumn{2}{|c|}{ Tonsillectomy } & \multirow[b]{2}{*}{ p } \\
\hline & Yes & No & & Yes & No & \\
\hline \multicolumn{7}{|c|}{ UC, anti-TNF, n (\%) } \\
\hline Yes & $0(0.0)$ & $9(10.2)$ & \multirow{2}{*}{0.514} & $1(14.3)$ & $8(9.6)$ & \multirow{2}{*}{0.708} \\
\hline No & $2(100)$ & 79 (89.8) & & $6(85.7)$ & $75(90.4)$ & \\
\hline \multicolumn{7}{|c|}{ CD, anti-TNF, n (\%) } \\
\hline Yes & $4(50)$ & $12(36.4)$ & \multirow{2}{*}{0.482} & $1(50)$ & $15(38.5)$ & \multirow{2}{*}{0.748} \\
\hline No & $4(50)$ & 21 (63.6) & & $1(50)$ & $24(61.5)$ & \\
\hline
\end{tabular}




\section{Tonsillectomy}

Results of this study stated that 7 (7.8\%) patients with UC, 2 (4.9\%) patients with CD, and 5 (6.7\%) patients in the HCs had undergone tonsillectomy. No significant difference was observed among the groups in terms of tonsillectomy $(p=0.828$; Table 1). However, 2 patients with CD had tonsillectomy after the age of 20, and it was a significant difference compared with the HCs ( $p=0.014$; Table 2). In IBD patients, the relationship between tonsillectomy and the onset time and location of the disease was not significant ( $>0.05$; Table 5).

\begin{tabular}{|c|c|c|c|}
\hline & \multicolumn{2}{|l|}{ Appendectomy } & \multirow[t]{2}{*}{$p$} \\
\hline & Yes & No & \\
\hline UC, n (\%) & $2(2.2)$ & $88(97.8)$ & - \\
\hline Disease onset age, median (IQR) & $46.5(38.0-55.0)$ & $32.0(25.0-42.0)$ & 0.136 \\
\hline Smoker, n (\%) & $0(0.0)$ & $30(34.1)$ & 0.200 \\
\hline \multicolumn{4}{|l|}{ Location, n (\%) } \\
\hline Proctitis & $0(0.0)$ & $12(13.6)$ & \multirow{4}{*}{0.563} \\
\hline Distal colitis & $0(0.0)$ & $20(22.7)$ & \\
\hline Left-sided colitis & $1(50.0)$ & $18(20.5)$ & \\
\hline Pancolitis & $1(50.0)$ & $38(43.2)$ & \\
\hline CD, n (\%) & 8 (19.5) & $33(80.5)$ & - \\
\hline Disease onset age, median (IQR) & $35.0(20.5-43.0)$ & $32.0(29.0-38.0)$ & 0.834 \\
\hline Smoker, n (\%) & $4(50.0)$ & $14(42.4)$ & 0.699 \\
\hline \multicolumn{4}{|l|}{ Location, n (\%) } \\
\hline Ileum & $3(37.5)$ & $14(43.8)$ & \multirow{3}{*}{0.429} \\
\hline Colon & $0(0.0)$ & $3(9.4)$ & \\
\hline Ileocolon & $5(62.5)$ & $15(46.9)$ & \\
\hline
\end{tabular}

\begin{tabular}{|c|c|c|c|}
\hline & \multicolumn{2}{|l|}{ Tonsillectomy } & \multirow[t]{2}{*}{$\mathbf{p}$} \\
\hline & Yes & No & \\
\hline Disease onset age, median (IQR) & $38.0(22.0-46.0)$ & $32.0(25.0-43.0)$ & 0.619 \\
\hline Smoker, n (\%) & $1(14.3)$ & $29(34.9)$ & 0.234 \\
\hline Proctitis & $0(0.0)$ & $12(14.5)$ & \multirow{4}{*}{0.464} \\
\hline Distal colitis & $2(28.6)$ & $18(21.7)$ & \\
\hline Left-sided colitis & $1(14.3)$ & $18(21.7)$ & \\
\hline Pancolitis & $4(57.1)$ & $35(42.2)$ & \\
\hline $\mathrm{CD}, \mathrm{n}(\%)$ & $2(4.9)$ & $39(95.1)$ & - \\
\hline \multicolumn{4}{|l|}{ Location, n (\%) } \\
\hline Ileum & $2(100.0)$ & $15(39.5)$ & \multirow{3}{*}{0.168} \\
\hline Colon & $0(0.0)$ & $3(7.9)$ & \\
\hline Ileocolon & $0(0.0)$ & $20(52.6)$ & \\
\hline
\end{tabular}




\section{DISCUSSION}

The relationship between appendectomy and IBD is considered complex. The appendix contains dense structures of lymphoid tissue, such as Peyer's patches. It is the most important region where immunoglobulin A is produced, which is very important for regulating the density and quality of the intestinal flora. Considering its shape and location, the appendix is also home for commensal bacteria in the body. Moreover, the appendix is of great importance as a microbiota reservoir (13). While some studies report an increased risk of $C D$ after appendectomy, there are studies reporting otherwise $(5,10,14,15)$. A study reporting that appendectomy affected the risk of developing CD based on age, gender, and operative diagnosis (perforated or nonperforated) also stated that appendectomy performed before the age of 10 reduced the risk of onset of $C D(10)$.

Another study reported that appendectomy performed at pediatric age did not pose a potential risk for incidence of pediatric CD. It also stated that undiagnosed early symptoms of CD could be confused with appendicitis symptoms (16). The impact of appendectomy on the clinical course of $C D$ is still controversial. Contrary to a few studies reporting no risk, appendectomy has been reported to increase surgical risk in CD patients $(17,18)$. Andersson et al. (10) reported that the increased surgical risk for CD was observed only in patients operated for perforated appendicitis. Furthermore, an increased risk of intestinal resection has been reported in $C D$ patients with a history of appendectomy after perforated appendicitis $(10,14)$.

Cosnes et al. (19) reported that CD patients with a history of appendectomy were associated with more proximal disease, greater risk of stenosis, and lesser anal fistula; however, appendectomy did not affect the severity of the disease. In addition, it was emphasized that immunosuppressant, immunomodulatory, and anti-tumor necrosis factor requirements are not affected by appendectomy independent of the localization of the disease. It is claimed that appendectomy and CD share common genetic and environmental characteristics, and appendectomy alone does not show any immunomodulatory effect (19).

In our study, history of appendectomy was higher in CD patients than in the control group. We found that appendectomy increased the risk of developing CD by 4.3 times. Therefore, appendectomy is an increased risk factor for patients with CD. In this study, appendectomy was performed in $75 \%$ of patients before the age of 20, and a diagnosis of CD was made at a mean time of 16 (13.3) years after appendectomy. Unlike our study, Kurina et al. (20) reported that appendectomy performed after the age of 20 was associated with an increased risk of $C D$ that will develop later. However, this risk was limited to those diagnosed with $\mathrm{CD}$ within an average of 1 year after appendectomy.

In our study, intestinal resection was not investigated in CD patients; however, no relationship was found between appendectomy and perianal disease, which is one of the poor prognostic factors for $\mathrm{CD}$. In addition, the history of appendectomy had no effect on the age at diagnosis of $C D$, site of intestinal involvement of the disease, and medical treatment. However, ileum involvement of $42.8 \%$ and ileocolonic involvement of 57\% was observed in all of the patients with appendectomy.

Many studies have claimed that the appendix has a physiological role in regulating the immunological response to the intestinal microflora and appendectomy reduces the risk of developing UC (21). A study investigating the relationship of appendectomy with incidence of UC, including only the patients with extensive and severe colitis, emphasized that appendectomy has a protective effect in UC patients. In other words, the study reported that the protective effect of appendectomy can only be explained for pancolitis and severe colitis (22). In the present study, we included all patients with left colon, distal, and rectal involvement in addition to pancolitis. We found no difference in disease location and medical treatment between UC patients who had undergone appendectomy and those who did not undergo appendectomy.

Many studies reported that performing appendectomy in childhood and adolescence causes a decrease in the risk of developing UC; however, the same effect is not valid for appendectomy in adults $(10,22)$. These findings suggest the presence of age-dependent differences in the pathogenesis of appendicitis. In addition, patients who underwent appendectomy before the diagnosis of $\mathrm{UC}$ have reduced risk of UC-related hospitalizations and colectomy (23). In our study, only two patients with UC had a history of appendectomy. Moreover, in both the patients, appendectomy was performed after the age of 20. Interpretation of the age of appendectomy in terms of the risk of development of UC was not possible because of the small number of patients included in this study.

The etiological relationship between tonsillectomy and incidence of both CD and UC remains unclear. Some studies have reported that performing tonsillectomy before the diagnosis of IBD does not have any relationship with the risk of onset of both UC and CD (20,24). In another study, no significant relationship was found between tonsillectomy and IBD (25). Another study showed that tonsillectomy was associated with an increased risk of developing CD; however, this relationship was not found in 
case of onset of UC (6). Similar to a study that reported ileum as the most common disease site in CD patients who had previously undergone tonsillectomy, in our study, ileum was involved in 2 CD patients who had previously undergone tonsillectomy (26).

\section{Study Limitations}

This study has few limitations. First, the effects of appendectomy and tonsillectomy on surgical history and disease activities associated with IBD could not be evaluated. In addition, inclusion of less number of patients who underwent appendectomy and tonsillectomy limits our research results on IBD disease location and treatment effect of these operations.

\section{CONCLUSION}

Findings of this study showed that appendectomy is associated with an increased risk of onset of $C D$, as an indication that appendectomy and CD have similar environmental or genetic characteristics. However, no effect of appendectomy could be observed on age at diagnosis, location of the disease, and medical treatment of UC and CD. We have shown that appendectomy does not increase the risk of developing UC. Furthermore, tonsillectomy is not associated with an increased risk of developing CD or UC.

\section{Ethics}

Ethics Committee Approval: Ethics Committee of the University of Health Sciences, University of Health Sciences Turkey, Prof. Dr. Cemil Tașçıoğlu City Hospital (number: E-48670771-514.10, date: 26.01.2021).

Informed Consent: Informed consent was obtained from all participants of this study for analysis and publication of their data for scientific purposes.

Peer-review: Externally peer-reviewed.

\section{Authorship Contributions}

Concept: Y.G., D.Ö.K., Design: Y.G., D.Ö.K., Data Collection or Processing: Y.G., D.Ö.K., Analysis or Interpretation: Y.G., D.Ö.K., Literature Search: Y.G., D.Ö.K., Writing: Y.G., D.Ö.K.

Conflict of Interest: No conflict of interest was declared by the authors.

Financial Disclosure: The authors declared that this study received no financial support.

\section{REFERENCES}

1. Bruce E, Sands and Corey A. Siegel. Crohn's Disease. Feldman M, Friedman LS, Brandt LJ, editors. Sleisenger \& Fordtran's Gastrointestinal and
Liver Disease. Pathophysiology/Diagnosis/Management Philadelphia: Saunders Elsevier; 2010. p.1041-973.

2. Fiocchi C. Inflammatory bowel disease: etiology and pathogenesis. Gastroenterology 1998;115:182-205.

3. Pierik M, Yang H, Barmada MM, Cavanaugh JA, Annese V, Brant SR, et al. The IBD international genetics consortium provides further evidence for linkage to IBD4 and shows gene-environment interaction. Inflamm Bowel Dis 2005;11:1-7.

4. Andreu-Ballester JC, Pérez-Griera J, Ballester F, Colomer-Rubio E, Ortiz-Tarín I, Peñarroja Otero C. Secretory immunoglobulin A (sIgA) deficiency in serum of patients with GALTectomy (appendectomy and tonsillectomy). Clin Immunol 2007;123:289-97.

5. López Ramos D, Gabriel R, Cantero Perona J, Moreno Otero R, Fernández Bermejo M, Maté Jiménez J. Association of MALTectomy (appendectomy and tonsillectomy) and inflammatory bowel disease: a familial casecontrol study. Rev Esp Enferm Dig 2001;93:303-14.

6. Sun W, Han X, Wu S, Yang C. Tonsillectomy and the risk of inflammatory bowel disease: A systematic review and meta-analysis. J Gastroenterol Hepatol 2016;31:1085-94.

7. Mitchell SA, Thyssen M, Orchard TR, Jewell DP, Fleming KA, Chapman RW. Cigarette smoking, appendectomy, and tonsillectomy as risk factors for the development of primary sclerosing cholangitis: a case control study. Gut 2002;51:567-73.

8. Cooper C, Pippard EC, Sharp H, Wickham C, Chamberlain MA, Barker DJ. Is Behçet's disease triggered by childhood infection? Ann Rheum Dis 1989;48:421-3.

9. Kaplan GG, Jackson T, Sands BE, Frisch M, Andersson RE, Korzenik J. The risk of developing Crohn's disease after an appendectomy: a metaanalysis. Am J Gastroenterol 2008;103:2925-31.

10. Andersson RE, Olaison G, Tysk C, Ekbom A. Appendectomy is followed by increased risk of Crohn's disease. Gastroenterology 2003;124:40-6.

11. Loftus Jr EV. Clinical epidemiology of inflammatory bowel disease: Incidence, prevalence, and environmental influences. Gastroenterology 2004;126:1504-17.

12. Montgomery SM, Pounder RE, Wakefield AJ. Smoking in adults and passive smoking in children are associated with acute appendicitis. Lancet 1999;353:79.

13. Girard-Madoux MJH, Gomez de Agüero M, Ganal-Vonarburg SC, Mooser C, Belz GT, Macpherson AJ, et al. The immunological functions of the Appendix: An example of redundancy? Semin Immunol 2018;36:31-44.

14. Frisch M, Johansen C, Mellemkjaer L, Engels EA, Gridley G, Biggar RJ, et al. Appendectomy and subsequent risk of inflammatory bowel diseases. Surgery 2001;130:36-43.

15. Sicilia B, López Miguel C, Arribas F, López Zaborras J, Sierra E, Gomollón F. Environmental risk factors and Crohn's disease: a population-based, case-control study in Spain. Dig Liver Dis 2001;33:762-7.

16. Castillo Fernández AL, Paredes Esteban RM, Villar Pastor CM, Ruiz Hierro C, Lasso Betancor CE, Vargas Cruz V, et al. Apendicectomía y enfermedad de Crohn [Appendectomy and Crohn's disease]. Cir Pediatr 2013;26:5-8.

17. Radford-Smith GL, Edwards JE, Purdie DM, Pandeya N, Watson M, Martin NG, et al. Protective role of appendicectomy on onset and severity of ulcerative colitis and Crohn's disease. Gut 2002;51:808-13.

18. Riegler G, Caserta L, Esposito I, De Filippo FR, Bossa F, Esposito P, et al. Worse clinical course of disease in Crohn's patients with previous appendectomy. Eur J Gastroenterol Hepatol 2005;17:623-7. 
19. Cosnes J, Seksik P, Nion-Larmurier I, Beaugerie L, Gendre JP. Prior appendectomy and the phenotype and course of Crohn's disease. World J Gastroenterol 2006;12:1235-42.

20. Kurina LM, Goldacre MJ, Yeates D, Seagroatt V. Appendicectomy, tonsillectomy, and inflammatory bowel disease: a case-control record linkage study. J Epidemiol Community Health 2002;56:551-4.

21. Vcev A, Pezerovic D, Jovanovic Z, Nakic D, Vcev I, Majnaric L. A retrospective, case-control study on traditional environmental risk factors in inflammatory bowel disease in Vukovar-Srijem County, northeastern Croatia, 2010. Wien Klin Wochenschr 2015;127:345-54.

22. Andersson RE, Olaison G, Tysk C, Ekbom A. Appendectomy and protection against ulcerative colitis. N Engl J Med 2001;344:808-14.
23. Myrelid P, Landerholm K, Nordenvall C, Pinkney TD, Andersson RE. Appendectomy and the Risk of Colectomy in Ulcerative Colitis: A National Cohort Study. Am J Gastroenterol 2017;112:1311-9.

24. Firouzi F, Bahari A, Aghazadeh R, Zali MR. Appendectomy, tonsillectomy, and risk of inflammatory bowel disease: a case control study in Iran. Int J Colorectal Dis 2006;21:155-9.

25. Xiong HF, Wang B, Zhao ZH, Hong J, Zhu Y, Zhou X, et al. Tonsillectomy and inflammatory bowel disease: a meta-analysis. Colorectal Dis 2016;18:145-53.

26. Maté-Jimenez J, Correa-Estañ JA, Perez-Miranda M, Gomez-Cedenilla A, Pajares JM, Moreno-Otero R. Tonsillectomy and inflammatory bowel disease location. Eur J Gastroenterol Hepatol 1996;8:1185-8. 